\title{
First transapical implantation in Poland of the aortic valve bioprosthesis registered both for aortic stenosis and insufficiency
}

\author{
Pierwsze w Polsce przezkoniuszkowe wszczepienie protezy biologicznej \\ zarejestrowanej dla niedomykalności i stenozy aortalnej \\ Robert Sobczyński ${ }^{1}$, Dariusz Dudek ${ }^{2}$, Piotr Mazur ${ }^{1,3}$, Łukasz Rzeszutko², Jerzy Sadowski ${ }^{1,3}$ \\ ${ }^{1}$ The John Paul II Hospital, Krakow, Poland \\ ${ }^{2} 2^{\text {nd }}$ Department of Cardiology, Jagiellonian University Medical College, Krakow, Poland \\ ${ }^{3}$ Institute of Cardiology, Jagiellonian University Medical College, Krakow, Poland
}

An 86-year-old man (body mass index $26.2 \mathrm{~kg} / \mathrm{m}^{2}$ ), suffering from severe symptomatic aortic stenosis, with a history of stable coronary artery disease, type 2 diabetes mellitus, hypertension, chronic obturatory pulmonary disease (COPD), and paroxysmal atrial fibrillation, who had undergone prostatectomy, sigmoidectomy for cancer, and biliary and pancreatic tracts stenting for a benign pancreatic mass, was admitted to our institution after the heart-team qualification for TAVI (EuroSCORE II 9.86\%, STS score 31.202\%). Six months prior to admission, he had been hospitalised in the cardiology ward and received percutaneous coronary intervention with stent implantation to the left main coronary artery and balloon aortic valvuloplasty (BAV) as part of hybrid treatment. On admission, he presented with exertional dyspnoea (NYHA class III). Transthoracic echocardiogram demonstrated preserved left ventricular (LV) function (LVEF 45\%) and aortic stenosis (AVA $1 \mathrm{~cm}^{2}$, AVAI $0.54 \mathrm{~cm}^{2}$, mean and maximal gradients: $31 \mathrm{~mm} \mathrm{Hg}$ and $51 \mathrm{~mm} \mathrm{Hg}$, respectively) with mild aortic regurgitation (AR) and moderate mitral regurgitation. Contrast-enhanced computed tomography revealed tortuous iliac arteries, massive calcifications of the aortic valve and diffuse calcifications of aorta (Fig. 1A-D). The procedure was performed with trans-oesophageal echocardiography (TOE) monitoring under general anaesthesia through a left antero-lateral mini-thoracotomy (sixth intercostal space). A 6 French catheter was placed in the right femoral artery. After exposure of the apex, two-layer pledgeted purse-string sutures were placed and epicardial electrodes implanted. After apical puncture, a soft J-tip guidewire was advanced into the descending aorta and exchanged using right Judkins for an extrastiff guidewire.

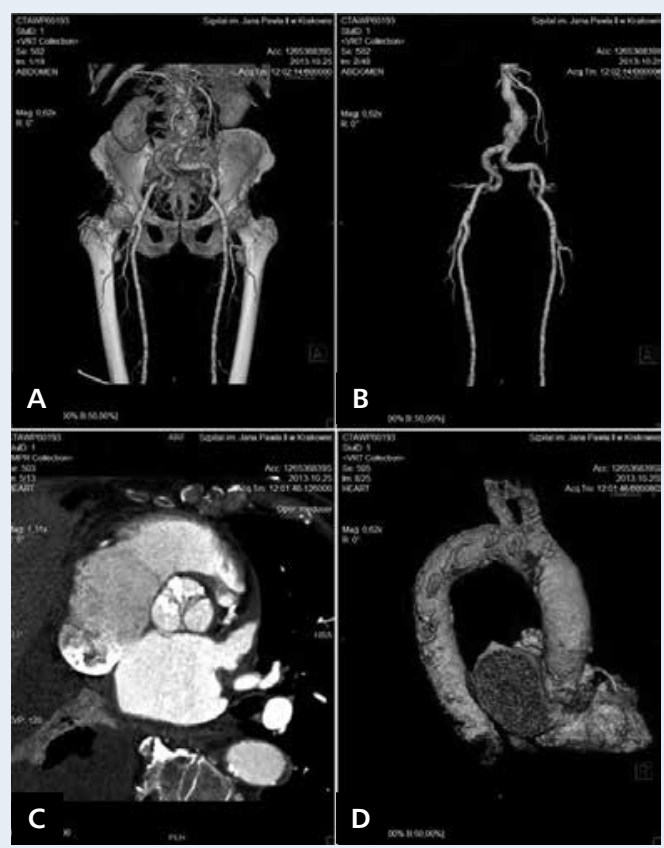

Figure 1. Computed tomography angiograms showing tortuous iliac arteries (A, B), calcifications of aortic valve (C) and diffuse calcifications of aorta (D)
A 12 French sheath was introduced into the LV and preprocedural BAV was performed using a $25 \mathrm{~mm}$ balloon (NuCLEUS, PFM Medical, Koeln, Germany) under rapid pacing, while the catheter and a $25 \mathrm{~mm}$ JenaValve were prepared. The delivery system was advanced into the $\mathrm{LV}$ and through the native valve into the ascending aorta. Feelers were positioned in Valsalva sinuses, and the valve was deployed. Additional BAV was required to obtain full unfolding and good valve function on angiography (Fig. 2). Periprocedural TOE revealed mild AR; in a follow-up TTE during the hospitalisation it subsided completely. In electrocardiography, a transient left bundle branch block was observed,

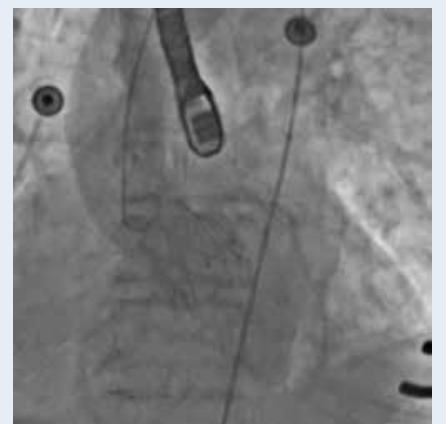

Figure 2. Angiogram showing JenaValve prosthesis in position after successful implantation but from $24 \mathrm{~h}$ postoperatively to discharge, no conduction blocks were recorded. Postoperatively, four packed red blood cells and one platelets concentrate transfusions were administered. Intensive ventilatory rehabilitation was applied for exacerbated COPD. Follow-up echocardiography revealed no AR. Transient psychotic symptoms were observed, but they subsided before discharge on postoperative day 17 .

Address for correspondence:

Robert Sobczyński, MD, PhD, John Paul II Hospital, ul. Prądnicka 80, 31-202 Kraków, Poland, tel: +48 12 6143075, fax: +48 12 4233900, e-mail: sobczynski@poczta.fm

Conflict of interest: none declared 